\title{
A Novel Approach to Breast Lesions
}

\author{
Dr Som Biswas ${ }^{1 *}$, Srirupa Biswas ${ }^{2}$ \\ ${ }^{1}$ Resident, Dept of Radiodiagnosis, GRMC, Gwalior \\ ${ }^{2}$ Assistant Professor, School of Pharmacy, ITM University, Gwalior
}

*Corresponding Author: Dr. Som Biswas, Resident, Dept of Radiodiagnosis, GRMC, Gwalior. India, Email: sombiswas4@gmail.com

\begin{abstract}
Introduction: Breast is an exocrine gland located in the subcutaneous tissue in front of the upper chest. It functions as a source of nutrition for the infant and is also a secondary sexual organ of the female.

Aim: Our aim is to prospectively evaluate breast lesions using Ultrasonography (USG) in combination with FNAC correlation

Objectives: The aim of Ultrasonography (USG) as a diagnostic tool for breast diseases is to study the mode of presentation, nature of the lesion, USG features and their correlation with clinical sign and symptoms and cytological study. Further, the study of Ultrasonography can enable the surgeon on ultimate clinical diagnosis and on compairing with FNAC enables the surgeon on planning the line of treatment.
\end{abstract}

Summary: 106 female patients having breast symptoms were evaluated in our department with USG breast and subsequently by FNAC.

Conclusion: USG independently detected 10 patients as suspicious of breast carcinoma and missed 8 lesions, which were subsequently proved as carcinoma. USG falsely detected two patients as suspicious lesion, which proved benign in FNAC. The sensitivity, specificity, PPV\& NPV of ultrasonography in detecting Ca breast are $55.55 \%, 97.72 \%, 83.33 \%$ and $91.48 \%$ respectively.

Keywords: Ultrasonography, FNAC, breast

\section{INTRODUCTION}

Breast is an exocrine gland located in the subcutaneous tissue in front of the upper chest. It functions as a source of nutrition for the infant and is also a secondary sexual organ of the female.

\subsection{Aim}

Our aim is to prospectively evaluate breast lesions using Ultrasonography (USG) in combination with FNAC correlation

\subsection{OBJECTIVES}

The aim of Ultrasonography (USG) as a diagnostic tool for breast diseases is to study the mode of presentation, nature of the lesion, USG features and their correlation with clinical sign and symptoms and cytological study. Further, the study of Ultrasonography can enable the surgeon on ultimate clinical diagnosis and on compairing with FNAC enables the surgeon on planning the line of treatment

\section{MATERIALS AND METHODS}

\subsection{Study Area}

At Department of Radio diagnosis in GAJRA RAJA MEDICAL COLLEGE \& J.A. groups of Hospital, GWALIOR

\subsection{Study Population}

Patients with complaints of breast pain, tenderness, breast lump, discharge or skin changes were scanned sonographically (irrespective of age / marital status/ breast feeding)

STUDY PERIOD : September 2015 To September 2016 (1 Year)

$\begin{array}{lll}\text { SAMPLE SIZE } & : & 106 \text { Patients } \\ \text { STUDY DESIGN } & : & \text { Prospective Study }\end{array}$

\subsection{Parameters to be Studied: on Usg}

Size, Margin, Location, Shape, Echogenicity, Calcification, Skin infiltration, internal echoes 
\& Posterior acoustic shadowing/ enhancement were studied.

\subsection{Study Tools}

USG machine Aloka Prosound alpha -6 (Aloka Trivitron Pvt. Ltd. Tokyo, Japan) Linear 6-12 $\mathrm{MHz}$ probe was used for real time scanning of breast lesions.

A detailed 'breast specific history' was taken including menstrual history, history of mastalgia, lactational history, past and family history of the patients.

Correlation of USG findings along with cytological findings was done.

\section{OBSERVATIONS AND RESUltS}

A group of 106 female patients with breast symptoms, such as pain breast, heaviness of the breasts, palpable mobile lump, hard lumps, fever with pain , nipple discharge and nipple retraction were examined

Table1. Age Distribution of the Patients

\begin{tabular}{|l|l|l|}
\hline Age of the patient & $\begin{array}{l}\text { Number of the } \\
\text { patient }\end{array}$ & \% \\
\hline$<40$ Years & 32 & 30 \\
\hline $41-50$ Years & 32 & 30 \\
\hline 51-60 Years & 24 & 23 \\
\hline Above 60 years & 18 & 17 \\
\hline
\end{tabular}

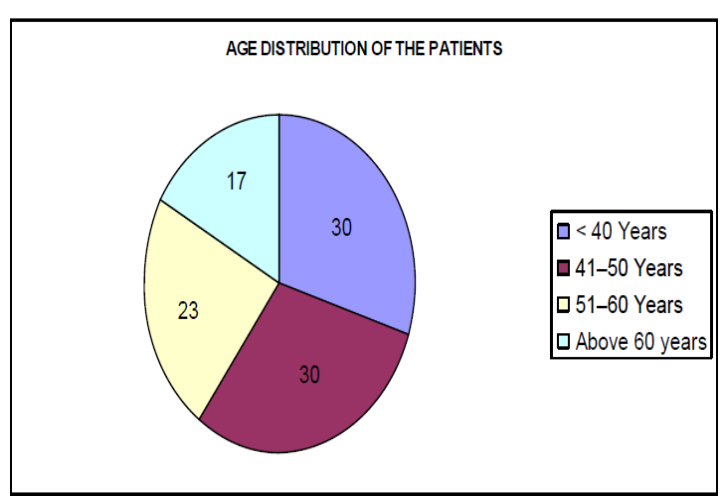

Chart1. Age Distribution of the Patients

\subsection{Ethnic Group Distribution}

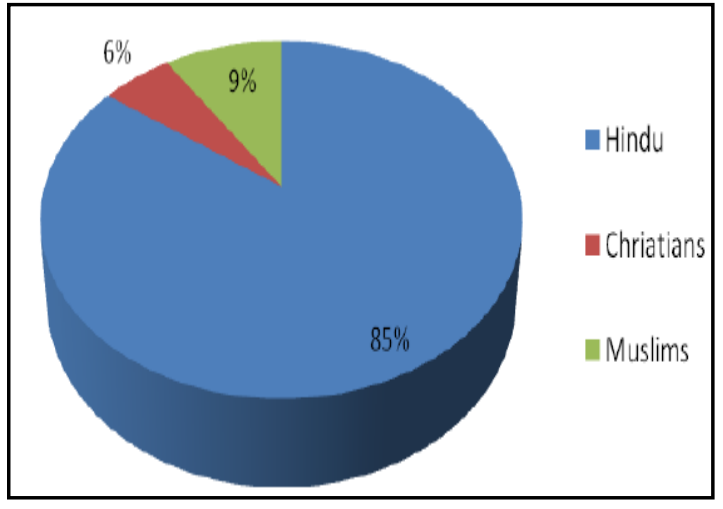

Chart2. Ethnic Group Distribution
The study included 106 females out of which 90 from Hindu religion, 10 from Muslim and 6 from Christian religion. Others religions were nil.

\subsection{Presenting Complaints of the Patient}

Among the patients 50 patients complains of mobile breast lump, 28 patients suffered from breast pain , 10 patients complained of hard lump, 6 patients felt heaviness, nipple discharge in 4 patients and nipple retraction \& lump with fever was the complains of 4 patients each.

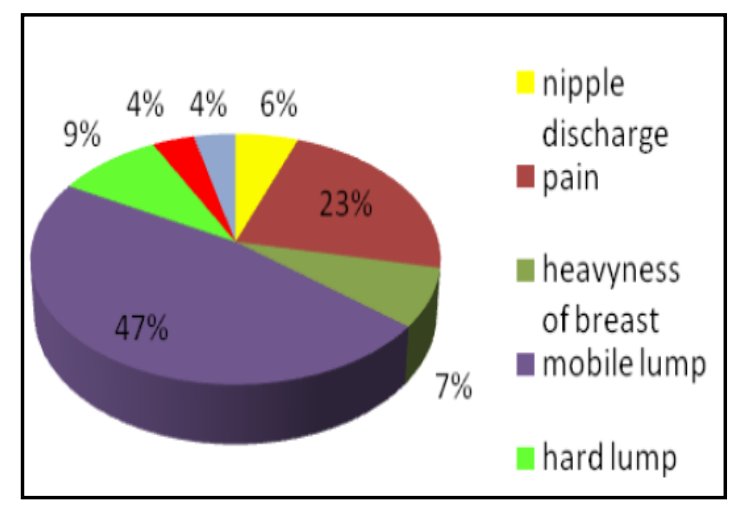

Chart3. Presenting Complaints of the Patient

\subsection{Distribution of Cases According to Risk Factors}

Table2. Distribution of Cases according to Risk factors

\begin{tabular}{|l|l|l|}
\hline \multicolumn{1}{|c|}{ Risk Factors } & \multicolumn{1}{c|}{$\begin{array}{c}\text { Number of } \\
\text { Cases }\end{array}$} & Percent \\
\hline $\begin{array}{l}\text { No associated Risk } \\
\text { factors }\end{array}$ & 72 & 68.0 \\
\hline Family History & 6 & 5.7 \\
\hline $\begin{array}{l}\text { Hormone Replacement } \\
\text { Therapy }\end{array}$ & 8 & 7.5 \\
\hline Late Menopause & 8 & 7.5 \\
\hline Oral Contraceptive Pill & 12 & 11.3 \\
\hline Total & 106 & 100.0 \\
\hline
\end{tabular}

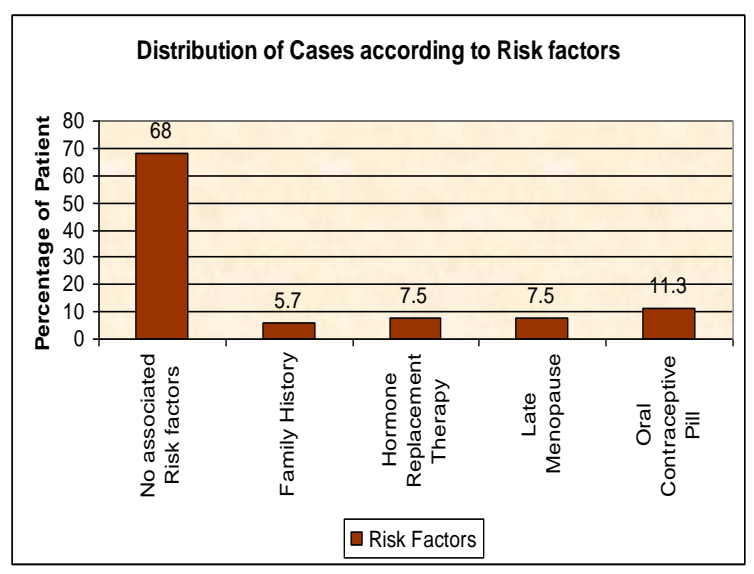

Chart4. Distribution of Cases According to Risk Factors 


\subsection{Risk Factor Analysis among the Patients Diagnosed as Carcinoma Breast}

Among 18 patients diagnosed as carcinoma breast four patients give history of hormone replacement therapy (HRT) after menopause.
Four patients have history of late menopause. Family history positive in two patients and history of oral contraceptive pill intake seen in two patients. There is no obvious risk factor found in six patients.

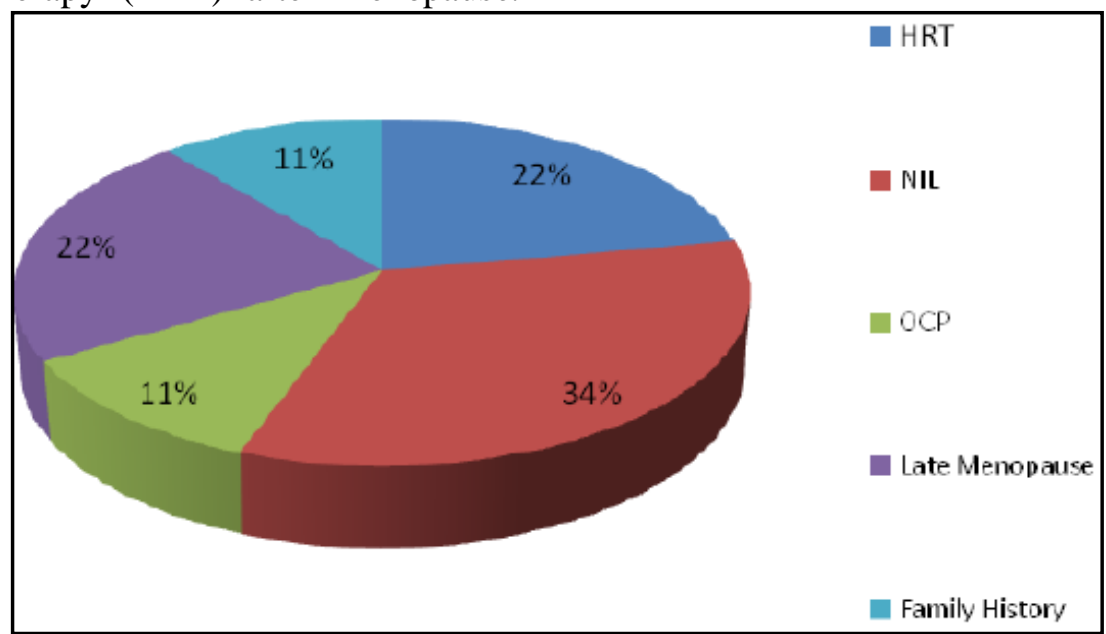

Chart5. Risk Factor Analysis among the Patients Diagnosed As Carcinoma Breast

3.5. Age Distribution of the Patients yrs, six patients are within 41-50 year group, Diagnosed as Carcinoma Breast four patients are between 51-60 year group and

Among the diagnosed cases of the carcinoma six patients belong to 61 and above group.

breast age of two patients are between 30-40

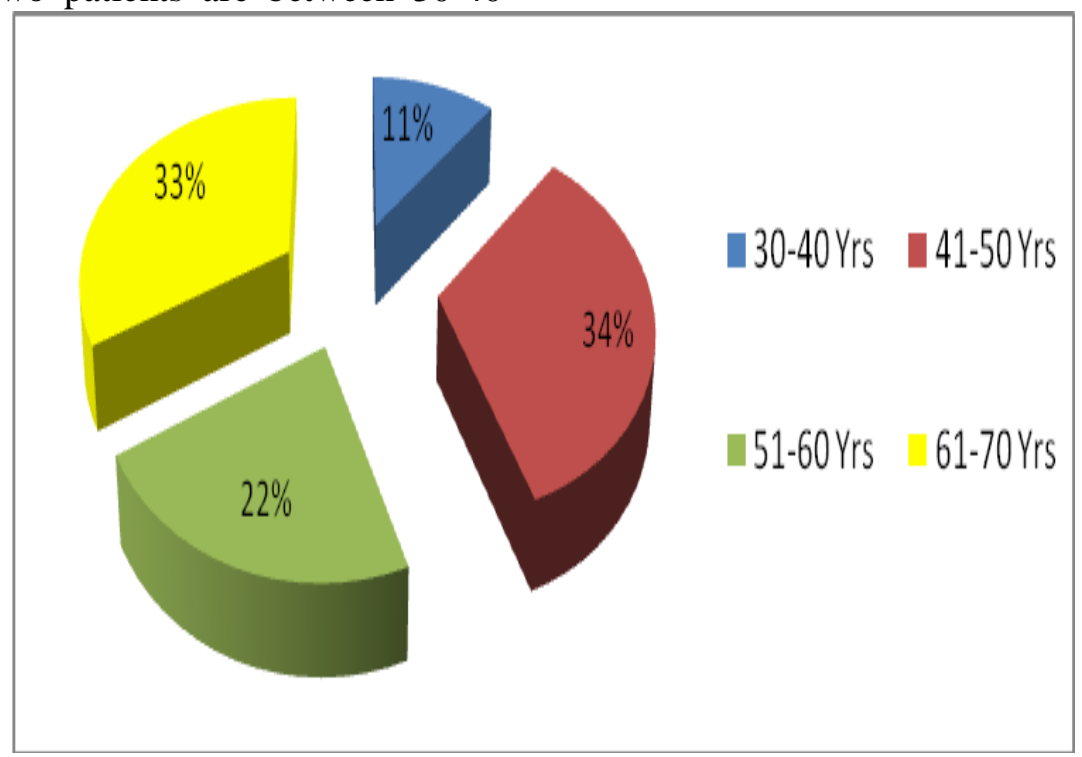

Chart6. Age Distribution of the Patients Diagnosed as Carcinoma Breast

\subsection{Clinical Examination}

The patients were examined clinically and they showed either movable well-defined masses with a stony hard consistency, or restricted mobility of ill-defined masses with stony hard consistency. Some patients showed diff use ill defined indurations with nipple discharge.

All the patients were given adequate explanation about the procedures and consent was obtained. These patients underwent USG of breasts and there after FNAC (according to the findings of
USG). The results obtained were correlated with each modality finding.

\section{Results OF THE USG}

The patients are evaluated by ultrasound and the lesions are analysed according to their characteristics. The distribution of the lesions, echo texture, margin, calcification and the other features are analysed. Below the table 6 shows the analysis of important and common findings of each lesion found in USG. 
Table3. Findings of the cases diagnosed by USG

\begin{tabular}{|c|c|c|c|c|c|c|}
\hline SI No & 1 & 2 & 3 & 4 & 5 & 6 \\
\hline cytology & $\begin{array}{l}\text { Fibrocystic } \\
\text { disease }\end{array}$ & fibroadenoma & Cyst & Infection & lipoma & Malignancy \\
\hline No of cases & 42 & 10 & 6 & 4 & 2 & 12 \\
\hline Quadrant & $\begin{array}{l}\text { Retroareolar } \\
\text { region }\end{array}$ & Scattered & Scattered & $\begin{array}{l}\text { Upper outer and } \\
\text { medial }\end{array}$ & ilq & $\begin{array}{l}\text { Retroareolar ilq } \\
\text { and slq }\end{array}$ \\
\hline $\begin{array}{l}\text { Bilateral/ } \\
\text { unilateral }\end{array}$ & Bilateral & Both & Unilateral & Unilateral & unilateral & Unilateral \\
\hline \begin{tabular}{|l|}
$\begin{array}{l}\text { Echogenecity } \\
\text { of the lesion }\end{array}$ \\
\end{tabular} & Hypoechoic & Hypoechoic & Anechoic & $\begin{array}{l}\text { Anechoic to } \\
\text { hypoechoic }\end{array}$ & isoechoic & $\begin{array}{l}\text { Heterogenous } \\
\text { echogenecity }\end{array}$ \\
\hline Margin & $\begin{array}{l}\text { Diffuse, } \\
\text { defined }\end{array}$ & 1 Well defined & Well defined & Well defined & Ill defined & Irregular \\
\hline calcification & 4 cases & $\begin{array}{l}\text { Coarse } \\
\text { calcification in } 6 \\
\text { cases }\end{array}$ & 5 & - & - & $\begin{array}{lrr}6 & \text { cases } & \text { show } \\
\text { microcalcification }\end{array}$ \\
\hline $\begin{array}{|ll|}\text { Single } & \text { or } \\
\text { multiple } & \\
\end{array}$ & diffuse & Single /multiple & single & Single & single & Single \\
\hline $\begin{array}{l}\text { Skin } \\
\text { infiltration }\end{array}$ & - & - & - & \begin{tabular}{|l} 
Focal \\
thickening in \\
one case
\end{tabular} & & \begin{tabular}{|lr}
6 & cases \\
thickening
\end{tabular} \\
\hline $\begin{array}{l}\text { With internal } \\
\text { echoes }\end{array}$ & & $\begin{array}{l}\text { Homogenously } \\
\text { filling up when } \\
\text { gain raised }\end{array}$ & $\begin{array}{l}\text { Central area } \\
\text { persistently } \\
\text { anechoic }\end{array}$ & $\begin{array}{l}\text { With internal } \\
\text { moving echoes. }\end{array}$ & & - \\
\hline $\begin{array}{l}\text { Without } \\
\text { internal } \\
\text { echoes }\end{array}$ & + & - & ++ & - & - & - \\
\hline $\begin{array}{l}\text { Posterior } \\
\text { enhancement }\end{array}$ & - & 4 cases & ++ & + & - & - \\
\hline $\begin{array}{l}\text { Posterior } \\
\text { shadowing }\end{array}$ & - & 4 cases & - & - & - & 10 cases \\
\hline
\end{tabular}

Four patients are having dense breast parenchyma. However on USG, the diagnosis was done correctly in those patients.

USG independently diagnosed 12 lesions as highly suspicious for malignancy and among them 10 patients revealed carcinoma in cytology. USG falsely diagnosed two lesions as highly suspicious, which was correctly diagnosed as fibroadenoma in cytology.

USG do not show suspicious lesions in 8 cytology proven carcinoma patients. There were 6 cases of cyst, which was clearly detected by USG.

Out of the 44 cases of fibrocystic diseases, USG confidently diagnosed 42 and missed only two.

Among 4 cases of infective pathology USG correctly diagnosed all the cases. Of 32 cases of fibroadenoma, USG detected 10. Finally in a case of lipoma of the breast, USG was successful independently

As mentioned above, of 44 cases of fibrocystic disease, USG could not diagnose 2 cases out of the 44 since the lesion appeared hypoechoic and showed no cysts or echogenic fibrous tissue. By the combined USG and FNAC approach all 44 cases were correctly diagnosed. In this study USG provided a better description of the lesions in fibrocystic diseases. A tiny cyst surrounded by echogenic fibrous tissue was the typical appearance on USG. This could be easily distinguished from carcinoma, which appears hypoechoic.

Out of the 4 confirmed cases of infective pathology, USG picked up all cases correctly. The case showed features of a simple cyst and was probably an infected cyst. The combined approach could do no better than USG alone. In our study, it was observed that abscesses had no definite shape and had irregular contours with weak internal echoes in either homogeneous or scattered distribution. Most of the abscesses also had moving echoes within them due to floating debris, which was an important differentiating feature. Some of them showed posterior acoustic enhancement, while others did not. However, none of them showed posterior acoustic shadowing. It was therefore concluded that most of the abscesses could be correctly diagnosed by USG. 
Table4. Comparative analysis of cytology, USG and combined study in detection of different breast lesions

\begin{tabular}{|l|l|l|l|}
\hline & \multicolumn{1}{|c|}{ CYTOLOGY } & \multicolumn{1}{c|}{ USG Alone } & Combined \\
\hline Fibrocystic disease & 44 & 42 & 44 \\
\hline Infection & 4 & 4 & 4 \\
\hline Fibroadenoma & 32 & 10 & 32 \\
\hline Cyst & 6 & 6 & 6 \\
\hline Carcinoma & 18 & 12 & 18 \\
\hline Lipoma & 2 & 2 & 2 \\
\hline Total & 106 & $76(71.6 \%)$ & $106(100 \%)$ \\
\hline
\end{tabular}

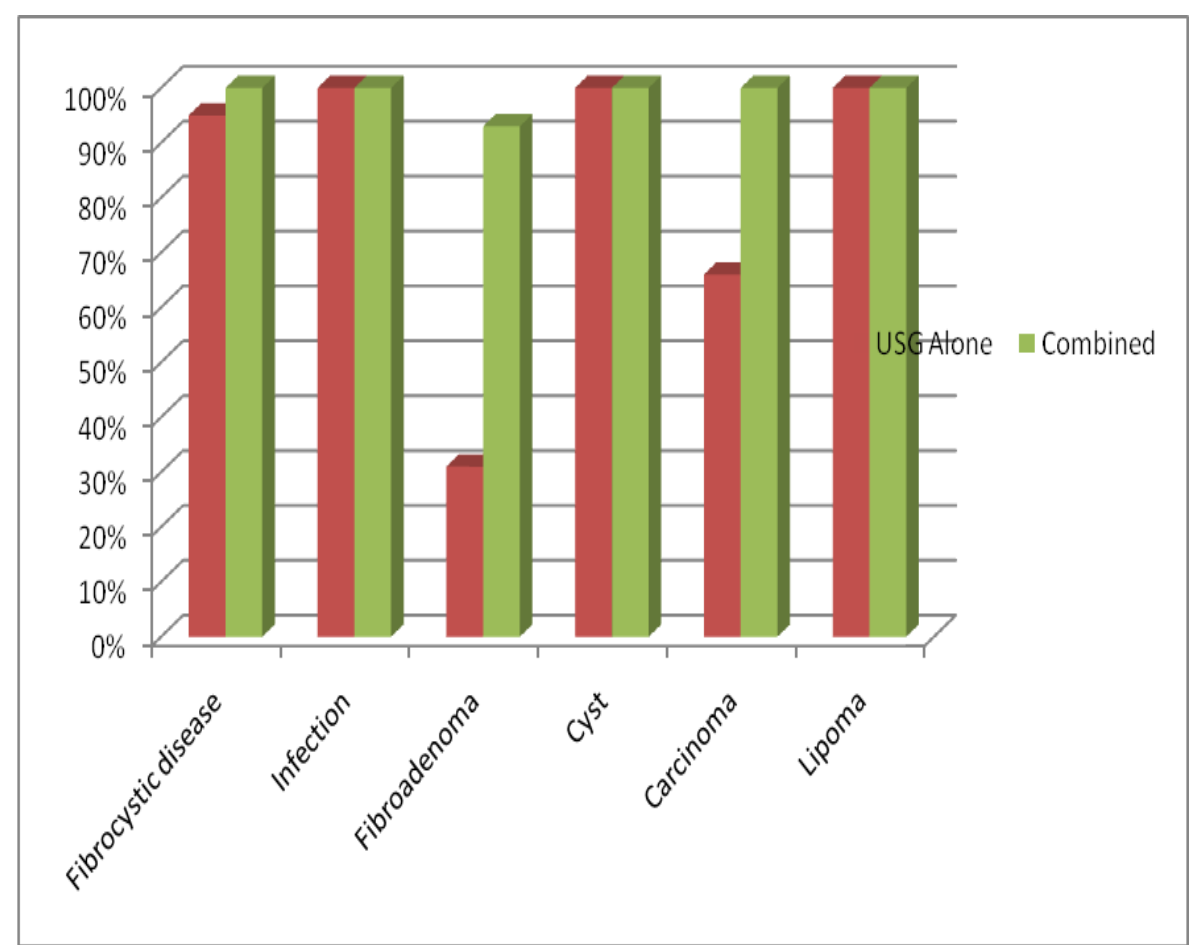

Chart7. Representation of the results of table-4 (according to percentage)

Table5. Correlation of USG and FNAC for diagnosis of Ca

\begin{tabular}{|l|l|l|l|}
\hline \multicolumn{1}{|c|}{ Ca } & \multicolumn{1}{c|}{ FNAC Positive } & \multicolumn{1}{c|}{ FNAC Negative } & \multicolumn{1}{c|}{ Total } \\
\hline Usg Positive & 10 & 2 & 12 \\
\hline USG Negative & 8 & 86 & 94 \\
\hline Total & 18 & 88 & 106 \\
\hline
\end{tabular}

Table6. Sensitivity\& specificity of USG

\begin{tabular}{|l|l|}
\hline Sensitivity & 55.6 \\
\hline Specificity & 97.7 \\
\hline Positive Predictive Value & 83.3 \\
\hline Negative Predictive Value & 91.5 \\
\hline Accuracy & 90.6 \\
\hline p<0.001 & \\
\hline
\end{tabular}

Table7. Distribution of cases According to USG diagnosis

\begin{tabular}{|l|l|l|}
\hline USG Diagnosis & Number of Cases & Percent \\
\hline Cyst & 8 & 7.5 \\
\hline Fibroadenoma & 10 & 9.4 \\
\hline Fibrocystic Disease & 42 & 39.6 \\
\hline Infection & 4 & 3.8 \\
\hline Lipoma & 2 & 1.9 \\
\hline Suspicious & 12 & 11.3 \\
\hline No Abnormality Detected & 28 & 26.4 \\
\hline Total & 106 & 100.0 \\
\hline
\end{tabular}




\section{USG Diagnosis}

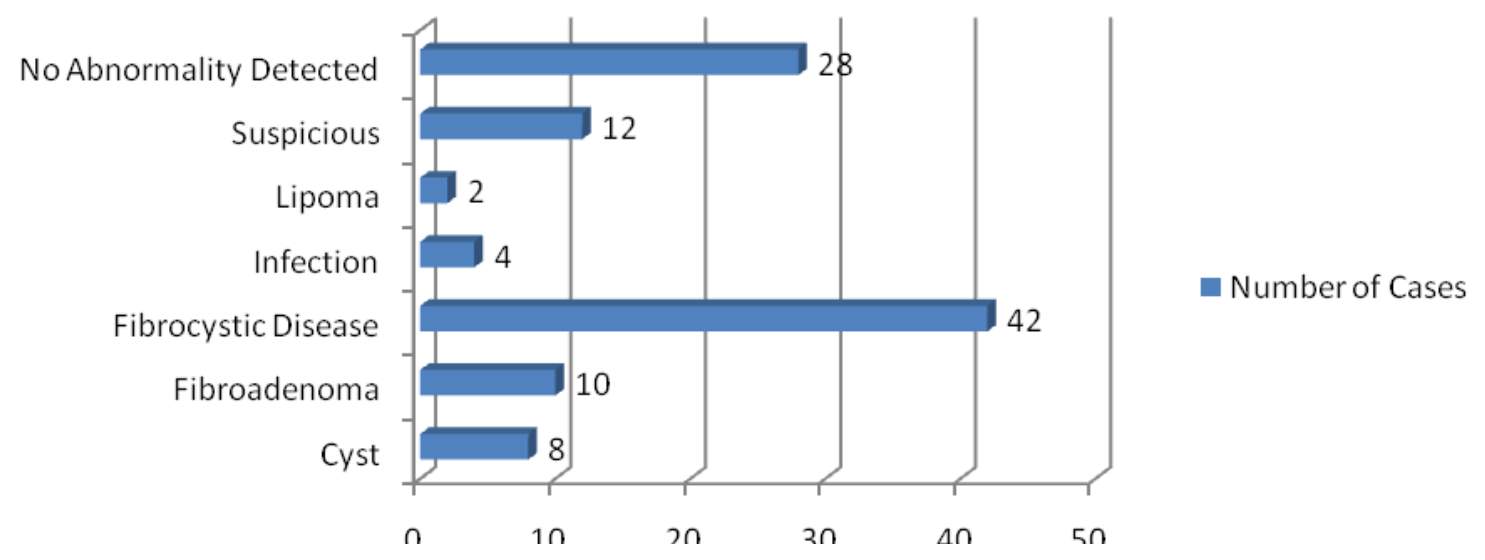

Chart8. Distribution Of Cases According To Usg Diagnosis

Table8. Distribution of Cases according to FNAC diagnosis

\begin{tabular}{|l|l|l|}
\hline \multicolumn{1}{|c|}{ FNAC Diagnosis } & \multicolumn{1}{c|}{ Number of Cases } & \multicolumn{1}{c|}{ Percent } \\
\hline Carcinoma & 18 & 17.0 \\
\hline Cyst & 6 & 5.7 \\
\hline Fibroadenoma & 30 & 28.3 \\
\hline Fibrocystic Disease & 46 & 43.4 \\
\hline Infection & 4 & 3.8 \\
\hline Lipoma & 2 & 1.9 \\
\hline Total & 106 & 100.0 \\
\hline
\end{tabular}

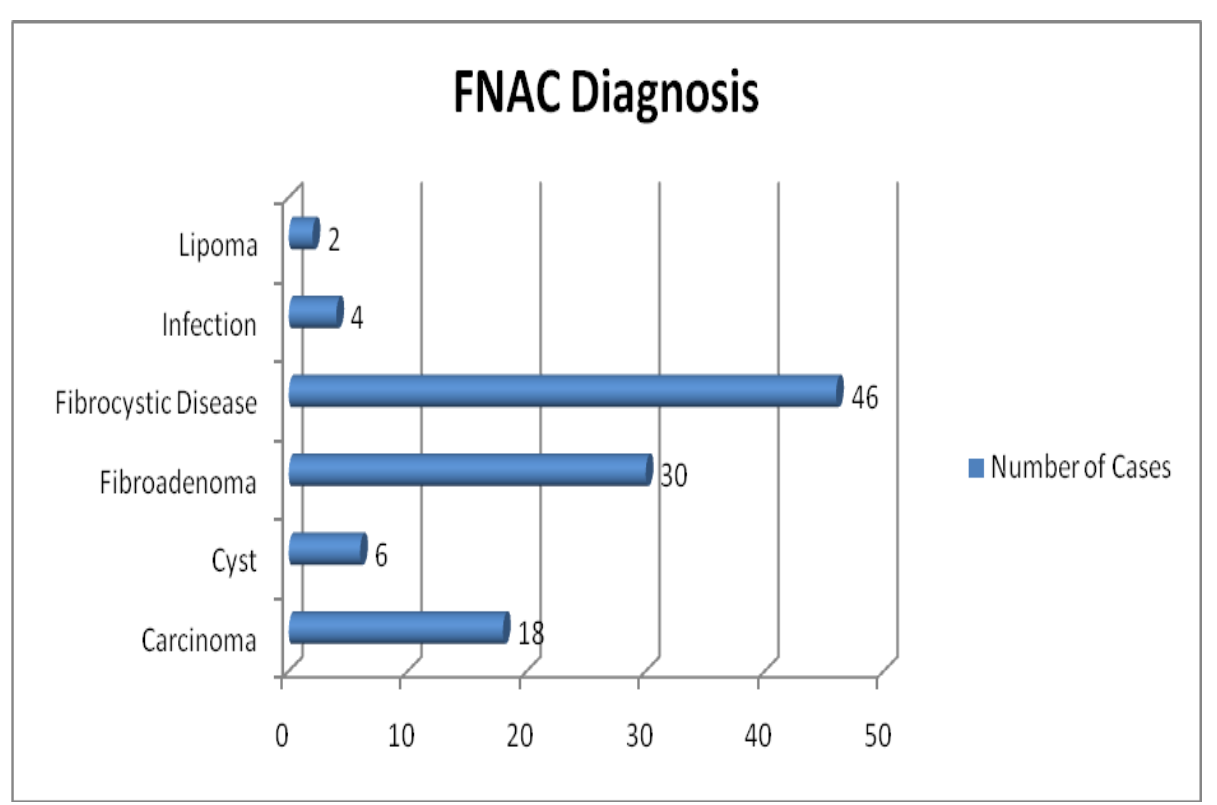

Chart9. Distribution of Cases According to Fnac Diagnosis

Table9. Correlation of cases between USG and FNAC

\begin{tabular}{|c|c|c|c|c|}
\hline & \multicolumn{2}{|c|}{ FNAC Code } & \multirow[t]{2}{*}{ Total } \\
\hline & & Benign Condition & Carcinoma & \\
\hline \multirow{3}{*}{ USG Diagnosis Code } & No Abnormality Detected & 28 & 0 & 28 \\
\hline & Benign Condition & 58 & 8 & 66 \\
\hline & Carcinoma & 2 & 10 & 12 \\
\hline \multicolumn{2}{|l|}{ Total } & 88 & 18 & 106 \\
\hline
\end{tabular}

Chi Square Test, $X^{2}=44.309, d f=2, P=<0.001$ Statistically significant

\subsection{ROC Curve Analysis}

To calculate Sensitivity and Specificity of USG to diagnose the carcinoma 


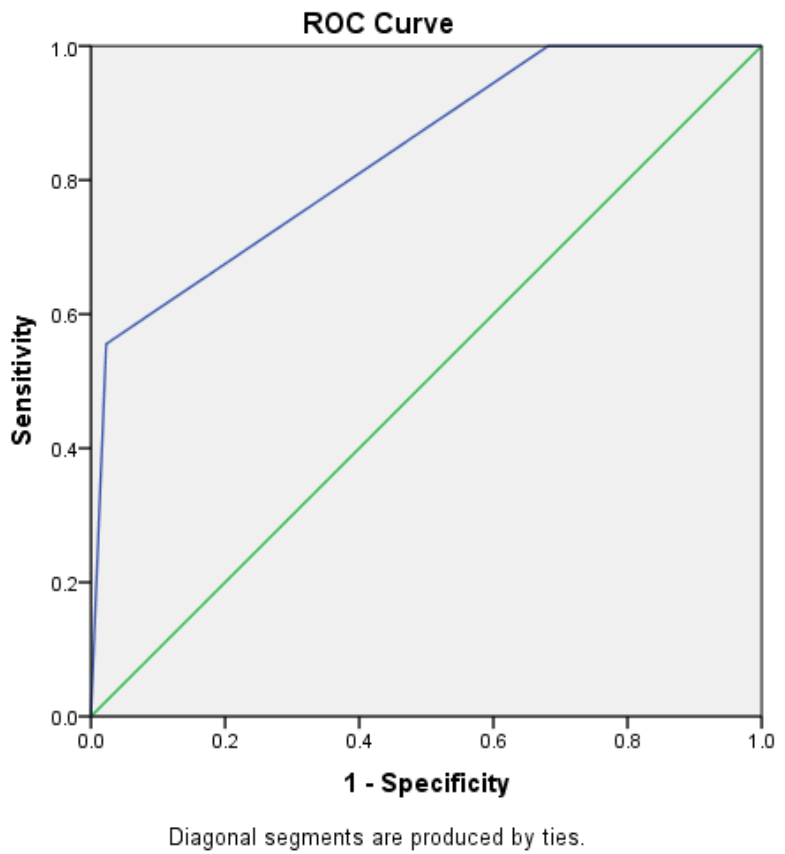

Table10. Area under curve (AUC) of the test

\begin{tabular}{|l|l|l|l|l|}
\hline \multicolumn{5}{|c|}{ Area Under the Curve (AUC) } \\
\hline Area & Std. Error ${ }^{\mathrm{a}}$ & Asymptotic Sig. & \multicolumn{4}{|l|}{ Asymptotic 95\% Confidence Interval } \\
& & & Lower Bound & Upper Bound \\
\hline 0.837 & 0.053 & 0.000 & 0.732 & 0.942 \\
\hline \multicolumn{5}{|c|}{ Coordinates of the Curve } \\
\hline Cut Off Point & & Sensitivity & Specificity \\
\hline 1.50 & & $55.6 \%$ & $97.7 \%$ \\
\hline
\end{tabular}

\section{DISCUSSION}

Breast cancer is one of the most prevalent cancers in the world among women. Breast masses are common and usually benign, but effective evaluation and prompt diagnosis can rule out malignancy.

In our study we examined every breast lesions by USG independently and then compared its result with FNAC result. Ying-Hua $\mathrm{Yu}$ et al. Conducted a study to prove 'Fine-needle aspiration biopsy (FNAC) of the breast is a minimally invasive yet maximally diagnostic method. The summary estimates for FNAC in diagnosis of breast carcinoma were as follows sensitivity, 0.927 (95\% confidence interval [CI], 0.921 to 0.933 ); specificity, 0.948 (95\% CI, 0.943 to 0.952 ); positive likelihood ratio, 25.72 (95\% CI, 17.35 to 28.13); negative likelihood ratio, 0.08 (95\% CI, 0.06 to 0.11); diagnostic odds ratio, 429.73 (95\% CI, 241.75 to 763.87 ). There conclusion was FNAC is an accurate biopsy for evaluating breast malignancy if rigorous criteria are used. With regard to unsatisfactory samples, further invasive procedures are required in order to minimize the chance of a missed diagnosis of breast cancer.
Rakhshindah Bajwa et al perfomed a study to evaluate the accuracy, utility and feasibility of Fine Needle Aspiration Cytology (FNAC) in diagnosing breast lesions in association with palpable size of the tumour. The study included 464 patients. Results were as follows: Using C1 - C5 categories of FNAC smears, 281 out of $464(60.6 \%)$ was categorized as C2 followed by C5 $48(10.3 \%)$. There was a significant $(\mathrm{P}<$ $0.0001)$ relationship between palpable size of the breast lesion and cytological category of the specimens. Fibroadenoma was the most frequent (161) (34.6\%) benign tumour, C3 accounted for $9.3 \%$ (43 out of 464). So the ultimate Conclusion was, The $\mathrm{C} 1$ - C5 grading system for FNAC is the most cost - effective and practical out patient procedure for early diagnosis of breast lesions.

Based on the above studies and the feasibility of the procedure in every patient, we have chosen FNAC for gold standard diagnostic tool.

Obenauer S. et al. performed to study to prove superiority of digital mammography over film screen mammography and they demonstrated digital mammography improved image quality compared with film-screen mammography. 
Micro calcification detection was also significantly better with the digital mammography system In our study, however mammography has not been used.

Breast carcinoma has been reported in only $4 \%$ of patients with breast symptoms, and even among palpable lesions undergoing biopsy, a large number of lesions turned out to be benign. The role of ultrasonography in patients with palpable breast lumps is to show a benign cause for palpable abnormality and to avoid further intervention, to support earlier intervention for a mass with malignant features, screen the remainder of the ipsilateral and contralateral breast for additional lesions, and to assess the extent of malignancy when cancer is diagnosed. However the false negative rate of mammography for breast cancer in patients with palpable abnormalities of the breasts has been reported to be as high as $16.5 \%$. Multiple studies have shown that the false negative rate for a combined mammographic and sonographic evaluation varies from $0 \%$ to $2.6 \%$. Additional imaging with sonography is appropriate in most instances, with the exception of lesions that are mammographically benign as noted above or lesions that are highly indicative of malignancy, in which sonographic imaging would not add any additional information. Sonography may obviate the need for intervention by showing benign causes of palpable abnormalities such as cysts, benign intra mammary lymph nodes, extravasated silicon and superficial thrombophlebitis of the breast.

Mahesh K. Shetty, et al, has conducted a study to evaluate the role of combined mammographic and sonographic imaging in patients with palpable abnormalities of the breast in Four hundred eleven consecutive cases. $40.1 \%$ had a benign assessment; $58.7 \%$ of the benign lesions were visible on both mammography and sonography; $40 \%$ of benign lesions were mammographically occult and identified at sonographic evaluation. In $14.6 \%$ of the 411 cases, imaging evaluation resulted in a suspicious assessment; $49(81.7 \%)$ of the 60 lesions categorized as suspicious underwent biopsy; $14(28.5 \%)$ of 49 lesions were histologically proved to be carcinoma. Nineteen $(31.6 \%)$ of the 60 lesions categorized as suspicious were mammographically occult and identified only on sonography; 14 (73.7\%) of these 19 lesions underwent biopsy; 12 (63.1\%) of 19 were benign, and $2(10.5 \%)$ were malignant. One hundred eighty-six $(45.2 \%)$ of the 411 palpable abnormalities had negative imaging assessment findings; 12 patients with negative imaging findings underwent biopsy, and all had benign findings. The sensitivity (14 of 14) and negative predictive value (186 of 186) for a combined mammographic and sonographic assessment were $100 \%$. In our study, $83.01 \%$ are benign lesions among 106 patients and out of which $72.72 \%$ of the lesions are diagnosed by USG alone. Out of 18 malignant lesions, USG detected 10. But when cytological correlation was done, there was $100 \%$ detection of the cancer. Combined mammographic and sonographic assessment was shown to be very helpful in identifying benign as well as malignant lesions causing palpable abnormalities of the breast.

Skaane $\mathrm{P}$ et al. evaluated ultrasound findings of 355 malignant breast tumours among 2,985 consecutive patients who underwent breast ultrasound were compared with clinical findings and pathologic subtypes of the tumours. They found a total of $97.5 \%$ of the palpable and $67.9 \%$ of the nonpalpable malignant neoplasms were detected as tumours on US. A negative predictive value of $100 \%$ in palpable and $96 \%$ in nonpalpable tumours was achieved using strict ultrasound criteria. In our study the sensitivity of the USG to detect the malignant lesion is 55\% in both palpable and nonpalpable breast lesion and specificity is $97.7 \%$. The negative predictive value is $91.4 \%$.

Thomas M. Kolb et al. Studied 221 women among them 246 cancers were found. Sensitivity, specificity, negative and positive predictive values, and accuracy of USG were $75.3 \%, 96.8 \%, 99.7 \%, 20.5 \%$, and $96.6 \%$, respectively. In our study, the sensitivity, specificity, NPV and PPV values of USG are $55 \%, 97.7 \%, 91.4 \%$ \& $83.3 \%$ respectively.

Corsetti V, et al showed that ultrasound detects early stage cancers in women with mammography negative dense breasts, with higher contribution in women younger than 50 years. In our study four cancer lesions in dense breasts were picked up clearly in USG.

Sonography therefore is a superior modality in patients with palpable abnormalities; its superiority over mammography is in being able to show lesions obscured by dense breast tissue and in characterizing palpable lesions that are mammographically visible or occult. Mammography is complimentary to sonography because of its ability to screen the reminder of the ipsilateral and contra lateral breast for clinically occult lesions. It has been reported 
that the accuracy of sonography is comparable with that of mammography as a screening modality for breast cancer. However the role of sonographic screening for additional lesions in the symptomatic patients has not been reported.

Dennis et al. retrospectively studied 600 lumps in 486 women with no focal ultrasonography mass or mammographic finding in the area of clinical concern. The study group included 540 lumps in 435 women who had a minimum mammographic and clinical follow-up of 2 years, as well as 60 additional lumps in 51 patients who underwent biopsy. No patient in the nonbiopsy group developed carcinoma at the initial site of concern during a mean mammographic and clinical follow-up period of 43 months, and all biopsy specimens were benign (negative predictive value- 100\%). Results of this retrospective study suggest that breast biopsy may be avoided in women with palpable abnormalities when both ultrasonography and mammography depict normal tissue at the lump site. In our study, ultrasound detected lesions in all the 18 patients of carcinoma breast and did not miss any lesion.

In our study we estimated chi square test and ROC curve analysis which was found to be statistically significant and this statistical finding leads us to the conclusion that with the use of the combination of USG and FNAC we can achieve the accuracy of $100 \%$ in detecting Breast Malignancy.

Masses within the breast (whether symptomatic or asymptomatic) are frequently diagnosed by USG. It is essential to define exactly what constitutes the lesion mass in order to differentiate benign from malignant lesions. Ultrasonography, the primary method of detection and diagnosis of breast disease has a proven sensitivity of $85 \%-95 \%$. However, additional diagnostic procedures often become necessary in view of its low specificity. Younger women have denser breasts, the use of oestrogen replacement therapy increases breast density and oestrogen replacement therapy use is most common during and shortly after the beginning of menopause and declines thereafter. In addition, dense breast parenchyma and younger age group are associated with high USG sensitivity. Presently non-invasive imaging methods like magnetic resonance imaging (MRI), thermography and nuclear studies are being used as adjunctive procedures. Though a definitive diagnosis is possible with non- invasive imaging procedures, for most lesions biopsy/fine needle aspiration cytology are essential for obtaining reliable results ' In the majority of cases surgical biopsy detects the lesion as benign and has served only to provide diagnosis, since surgical removal of these lesions is unnecessary unless the clinical signs and symptoms warrant for it.

Sonography is used as a modality to evaluate palpable masses, especially in women with dense breasts. Sonography often detects cysts or solid lesions that are obscured on the mammogram by the surrounding fibroglandular tissue and can reduce the number of surgical biopsies required when cysts are identified. Although the role of sonography initially was to establish or exclude the cystic nature of a mass, it has expanded with improvements in equipment and it plays very important roles in diagnosing and characterising the benign and malignant lesions of the breast. Evaluation of the axilla is a very important part of the breast diseases and it is effectively done by USG. USG can effectively distinguish solid masses from cysts, which account for approximately 25 percent of breast lesions. When strict criteria for cyst diagnosis are met, USG has a sensitivity of 89 percent and a specificity of 78 percent in detecting abnormalities in symptomatic women. Sonographic technology for breast imaging has dramatically improved in the last decade. With the advent of the colour Doppler study , elastography technique and sophisticated machine, more accurate diagnosis of the breast lesions possible in this era. However in this study, the doppler parameters of the breast lesions were not evaluated.

It was found from the literatures that USG is well-established diagnostic modality for the breast. It has high diagnostic yield, but is not $100 \%$ sensitive and specific. Cytology when combined with USG can yield very significant improvement in sensitivity and specificity for diagnosing different breast lesions and our study strongly supports this evidence.

\section{Summary \& CONClusion}

106 female patients having breast symptoms were evaluated in our department with USG breast and subsequently by FNAC.

USG independently detected 10 patients as suspicious of breast carcinoma and missed 8 lesions, which were subsequently proved as carcinoma. USG falsely detected two patients as suspicious lesion, which proved benign in 
FNAC. The sensitivity, specificity, PPV\& NPV of ultrasonography in detecting $\mathrm{Ca}$ breast are $55.55 \%, \quad 97.72 \%, \quad 83.33 \%$ and $91.48 \%$ respectively.

There are 4 malignant lesions in dense breast parenchyma and these were detected in USG. The eight cases of carcinoma breast which could not be picked up in USG were diagnosed by cytology.

In 44 FNAC proven cases of fibrocystic diseases, USG detected 42 cases. In 32 FNAC proven cases of fibroadenomas, USG detected 10 cases.Out of 6 benign cysts, USG detected all correctly. In 4 cases of infective pathology, USG correctly diagnosed all the cases.

In our study population $83.01 \%$ are benign and out of them $72.72 \%$ are diagnosed by USG alone.

The chi square test of USG correlation with FNAC is $\mathrm{X}^{2}=44.309 \& \mathrm{P}=<0.001$ which was found to be statistically significant which signify that USG is an effective diagnostic procedure of detecting breast malignancy, but on combination of ultrasonography with cytology shows strongest correlation.

USG is an individually effective diagnostic modality for detection of breast pathologies. In our study, there is a high rate of detection of breast carcinoma, however the accuracy of detection of breast carcinoma significantly improves when cytology was combined with USG. The study also implies that USG is better modality for detecting lesions in dense breasts.

This study confirms that ultrasound (USG) has significantly higher sensitivity and negative predictive value in detecting both benign and malignant lesions of the breast.

The statistical finding leads us to the conclusion that with the use of the combination of USG and FNAC we can achieve $100 \%$ accuracy in detecting breast lesions.
Thus sonography plays an important role in the management of breast lesions. Its applications includes

a. Characterisation of the breast lesions.

b. Avoiding unnecessary interventions in which imaging findings are unequivocally benign.

c. Negative findings on sonographic imaging

d. have very high specificity and are reassuring to the patient.

\section{REFERENCES}

[1] Warren Stafford, Science Heros Science, Herors. Com index. php.

[2] Raul Leborgne - Made New And Improved Mammograms. Science Heros. Com.

[3] Breast Xeroradiography; on analysis of our first 17 months, www.ncbi. nlm. nih.gov> NCBI > Literature > Pub Med Centre (OMC).

[4] The History of Breast ultrasound ibus.org/histmaterials/breast ultrasound.

[5] The History of Breast ulrasound www. Jultrasound med. org/content/ 23/7/887.

[6] Poster IO - UI Octoson and Ausonics www. Asum.com. an/newsite/files/documents/history/..../poster IO.pdf.

[7] Clarke D, Sudhakaran N, Gateley CA. Replace fine needle aspiration cytology with automated core biopsy in the triple assessment of breast cancer. Ann R Coll Surg Engl 2001; 83: 110-2.

[8] Schoonjans JM, Brem RF. Fourteen-gauge ultrasonographically guided large-core needle biopsy of breast masses. J Ultrasound Med 2001; 20:967-72.9.

[9] Annual report, 1984. National cancer registry. A project of Indian council of medical research, New Delhi 1987.

Citation: Dr Som Biswas \& Srirupa Biswas. A Novel Approach to Breast Lesions. ARC Journal of Surgery.2017; 3(4): 10-19. doi: dx.doi.org/ 10.20431/2455-572X. 0304003.

Copyright: (C) 2017 Authors. This is an open-access article distributed under the terms of the Creative Commons Attribution License, which permits unrestricted use, distribution, and reproduction in any medium, provided the original author and source are credited. 